Keio J. Med. 27: 53-57, 1978

\title{
GLUTEUS MAXIMUS MUSCLE ISLAND FLAPS FOR REPAIR OF SACRAL RADIATION ULCERS
}

\author{
YU MARUYAMA and SADAO TAJIMA \\ Department of Plastic and Reconstructive Surgery, \\ School of Medicine, Keio University, Tokyo, Japan
}

\begin{abstract}
A free gluteus maximus compound flap transfer to the chest was firstly reported by Fujino.1 The gluteus maximum muscle flap $2,3,4,5$ and recently developped musculocutaneous flap ${ }^{6}$ have been the chosen method of coverage of sacral pressure sores.

In this report, we present the gluteus maximus island flap successfully used in the reconstruction of sacral radiation ulcers.
\end{abstract}

\section{APPLIED ANATOMY}

The gluteus maximus muscle arises from the outer surface of the sacrum and the coccyx, and from the ligament of the sacrotuberous and the fascia covering the gluteus medius.

It is inserted into the iliotibial tract and the gluteal tuberosity of the femur. The blood supply is from the inferior and superior gluteal vessels which branch from the internal iliac vessels.

The nerve supply is the inferior gluteal nerve which runs parallel with the inferior gluteal vessels.

\section{OPERATIVE PROCEDURE}

The patient is placed in the prone position. Removing sorrounding altered tissues to the level of good minute blood supply, a superficial incision on the buttock is outlined. The outer surface of the gluteus maximus is severed and the gluteus maximum muscle is freed from the lateral origin.

On its posterior, the gluteal vessels in direct vision, are confirmed and, the 
dissection is performed proximally. (Fig. 2)

The gluteal muscle is cut in the proximal portion as large as is necessary to fill the defect, but care should be taken not to damage the nutrition vessels.

Then the gluteus maximus muscle island flap is elevated, repositioned and sutured to the debrided defect. (Fig. 3)

A thick split-skin graft is taken from the thigh and immediately attached to the muscle flap, without tieover dressing. (Fig. 4)

A suction drain is inserted under the donor site.

\section{CASE REPORTS}

Case 1

A 43-year-old fatty female was admitted with a painful $7 \times 8 \mathrm{~cm}$ pseudomonas infected sacral ulcer. She had had radiation treatment (number and intensity. of does unknown) after a total hysterectomy.

The ulcer developped about 3 years after the last irradiation. (Fig. 1)

An operation was performed in The wound was debrided and immediately closed with a muscle flap and a split skin. Postoperatively, the patient did well and her wound healed primarily. She has been under observation for 23 months since this surgery, and to date she has shown no evidence of breakdown.

\section{Case 2}

A 52-year-old fatty female had been suffering from sacral radiation ulcer asociated with relentless pain and a foul odor. The sacral ulcer was followed by radiation treatment of the carcinoma of the cervix of the uterus. (Fig. 6)

An attempt was made by another hospital to reconstruct the ulcer with two rotation-advancement buttock skin flaps, but the flaps developped necrosis.

In an operation was performed with a gluteus maximus muscle flap. Postoperatively, the patient did well. There was a small necrosis in the split skin graft, but it healed spontaneously within 2 weeks. She has been under observation for 17 months, and no problems have been noted. (Fig. 7)

\section{DISCUSSION}

Surgical procedures performed on radiation ulcers frequently present challenges because of problems such as poor wound healing, infection, necrosis and slough, malignant change, and progressive pathological changes.

Robinson ${ }^{7}$ described that the general principles of surgical procedures are 


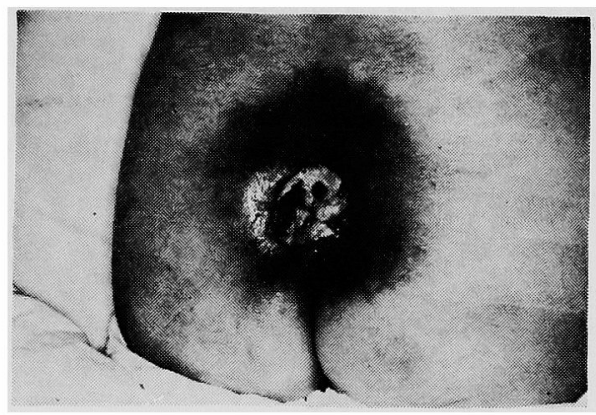

Fig. 1

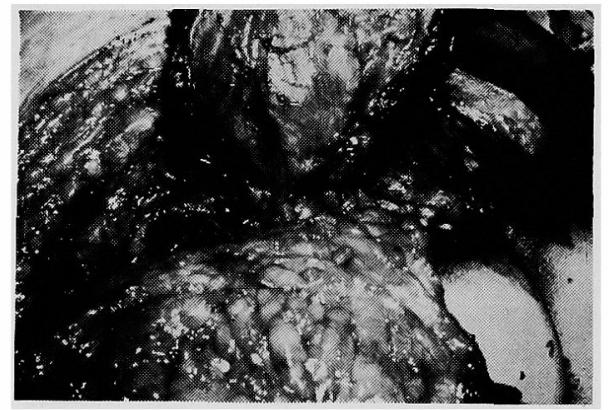

Fig. 2

Fig. 1 Preoperative view of the buttock. (Case 1)

A painfull pseudomonas infected round sacral ulcer. Hyper-pigmentation and radiation dermatitis are seen at the surrounding areas.

Fig. 2 On the posterior of a gluteus maximus muscle, the gluteal vessels are confirmed in direct vision. The muscle is cut as large as is necessary.

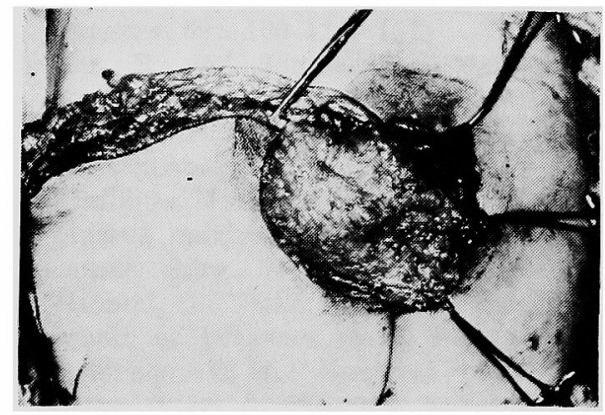

Fig. 3

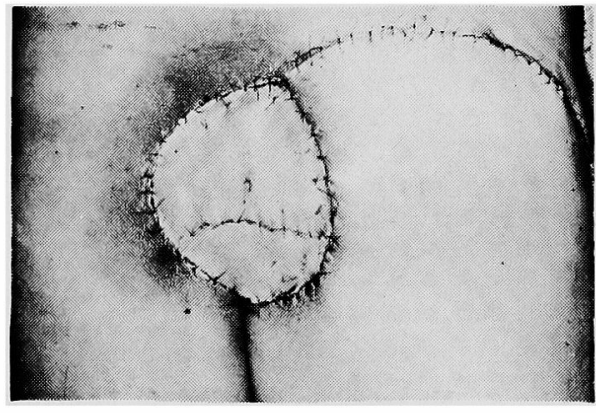

Fig. 4

Fig. 3 The gluteus maximus muscle flap is elevated, brought and sutured to the defect.

Fig. 4 Immediate result. S. T. S. G. is applied on the flap. 




Fig. 5

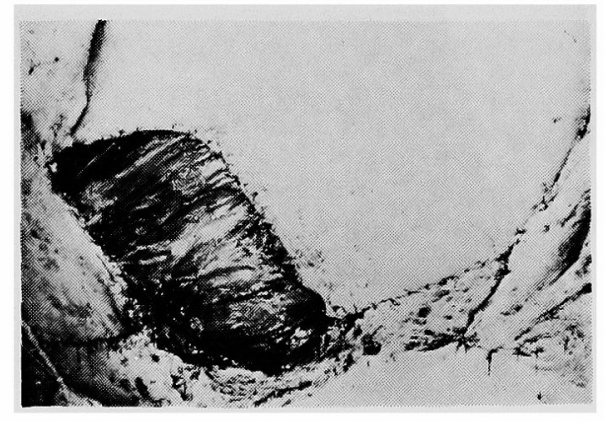

Fig. 6

Fig. 5 Results in 23 months after the operation.

Fig. 6 The gluteal maximus muscle flap is introduced to the defect in case 2. Two rotation-advancement buttock skin flaps were used before this surgery, but the flap developed necrosis by another hospital.



Fig. 7 No problem is noted on 17 months 
to remove altered tissue to the level of good minute blood supply, and to provide suitable coverage.

Barnes $^{8}$ stated that the coverage for the radiation ulcer should be as good as the blood supply that supports it.

Muscle is thought to be exactly the suitable coverage, from this point of view.

In the buttock region, gluteus maximus muscle flaps have several major advantages over randam skin flaps which we usually used before. In our cases transferred gluteus maximum muscle flaps worked well and showed no significant atrophy during the follow-up of up to 23 months.

In addition, in the case of sacral pressure sores, we, of course, have used gluteus maximum muscle or myocutaneous flaps with excellent results.

\section{SUMMARY}

Gluteus maximus island muscle flaps combined with a split skin graft were used to repair sacral radiation ulcers.

Cases and excellent follow up results are presented.

\section{REFERENCES}

1. Fujino, T., Harashina, T. and Aoyagi, F.: Reconstruction for apleasia of the breast and pectoral region by microvascular transfer of a free flap. Plast \& Reconstr. Surg. 56: 178-184, 1975. Discussion by Goldwyn 56: 335, 1975

2. Ger, R.: The surgical management of decubitus ulcers by muscle transposition, Surgery $69: 106-110,1971$

3. Ger, R. and Samuel, L.: Management of decubitus ulcers by muscle transplantation Plast \& Reconstr. Surg. 58: 419-428, 1976

4. Conway, H. and Griffith, B. H.: Plastic Surgery for closure of decubitus ulcers in patients with paraplegia. American Journal of Surgery 91: 946-955, 1956

5. Stallings, J. O., Delgado, J.P. and Converse, J.M.: Turn over island flap of gluteus maximus muscle for the repair of sacral decubitus ulcer. Plast \& Reconstr. Surg. 54: 52-54, 1974

6. Minami, T., Mills, R. and Parde, R.: Gluteus maximus myocutaneous flap for repair of pressure sores. Plast \& Reconstr. Surg. 60: 242-249, 1977

7. Robinson, D.W.: Surgical problems in the excision and repair of radiated tissue. Plast \& Reconstr. Surg. 55: 41-49, 1975

8. Barnes, W. E., Hoffman, G. W. and Pickrell, K.: Surgical treatment of irradation injuries of the perineum. Surg. Gynec. \& Obst. 118: 1067-1072, 1964 